\title{
Age-Related Changes in Circadian Rhythms and Their Effects on Cognition and Psychological Well-Being: A Literature Review
}

Aoife McMahon, BSc Student [1]*, Raymond Tolentino, BHSc Student [2], Phoebe Thum, BSc Student [1]

[1] Department of Biomedical Sciences, University of Guelph, Guelph, Ontario, Canada N1G 2W1

[2] Department of Health Sciences, McMaster University, Hamilton, Ontario, Canada L8S 4L8

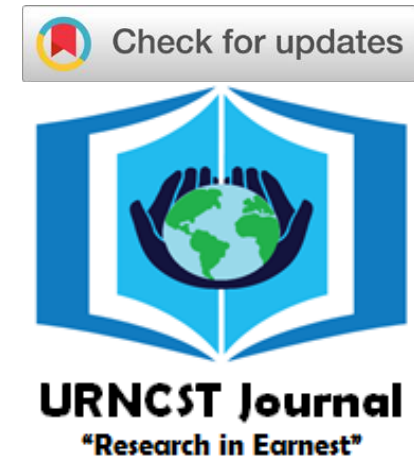

*Corresponding Author: amcmah02@uoguelph.ca

\begin{abstract}
Introduction: Circadian rhythms, the internal "clocks" that control a variety of physiological processes, have been found to change considerably throughout one's lifetime. Young adults tend to be more "evening" people, while older adults tend to be more "morning" people due to age-related changes in their sleep-wake cycles. This review aims to discuss the corresponding physiological and psychological changes that occur due to the changing circadian rhythms that come with age.

Methods: A literature search was conducted using the databases PubMed, PsycINFO, and AgeLine. Keywords included variations of "circadian rhythms", "aging", "chronotype", "cognition", "depression", "mood", "bipolar disorder", and "anxiety". Studies were selected and findings regarding the physiological and psychological changes due to circadian rhythms and aging were reviewed.

Results: Research shows that age-related disruptions in circadian rhythms are associated with cognitive and psychological decline. Diminished sleep quality is associated with older age, due to the aforementioned underlying dysregulated circadian rhythms. Sleep deprivation is associated with increased levels of fatigue, stress, and overall mood disturbances. Moreover, circadian rhythm abnormalities associated with old age are related to greater mood disturbances, depression, and anxiety.

Discussion: Poor sleep and older age are important factors that can negatively affect one's mood and emotional well-being. It is imperative that healthcare providers consider these factors when consulting and treating patients. Populations such as shift workers have been found to have impaired levels of alertness, mood, memory, and cognitive performance due to their dysregulated circadian rhythms. Furthermore, time of day plays a crucial role in the educational success of children and adolescents. Young individuals with an evening chronotype are put at a disadvantage for early school start times due to their opposing optimal times of performance.

Conclusion: Circadian rhythm dysfunction that is commonly associated with aging has the potential to contribute to adverse outcomes in human health, including cognitive deficits and pathological conditions. Future research efforts should concentrate on further clarifying the relationship between changing circadian rhythms and its impact on psychological well-being.
\end{abstract}

Keywords: circadian rhythms; aging; chronotype; cognition; depression; mood; bipolar disorder; anxiety

\section{Introduction}

As the saying goes, "the early bird catches the worm". This can be said for older adults who prefer to wake up early in the morning. Prior research has suggested that older adults tend to be more "morning" people, and younger adults tend to be more "evening" people [1]. This may be due to agerelated changes in circadian rhythms, or internal "clocks" that control a variety of physiological processes over a 24hour oscillatory cycle [2,3]. Circadian rhythms change considerably throughout one's lifetime, which are largely influenced by aging and morbidity [2]. Prolonged disruptions of circadian rhythms influence negative health consequences, which may be exacerbated in older adults $[2,4,5]$. Sleep and circadian rhythms play a large role in various domains of cognition [6]. For example, a decline in cognitive performance would be expected with sleep deprivation [3]. The mechanisms of how circadian rhythms change as one ages, as well as their effects, still remain unclear.

Chronotype is the variation of an individual's pattern of early or late time preference in activity [1,7]. Morning individuals have been shown to report increased energy and alertness, a stable personality, and more frequent positive emotions [1]. In contrast, evening people are usually active late and go to bed later in the night [7]. Age has been known to be a strong predictor of one's chronotype [1,7]. Dijk et al. [8] found that older adults who went to bed earlier (i.e., morning chronotype) had higher melatonin levels and lower 
UNDERGRADUATE RESEARCH IN NATURAL AND CLINICAL SCIENCE AND TECHNOLOGY (URNCST) JOURNAL Read more URNCST Journal articles and submit your own today at: https://www.urncst.com

body temperatures at earlier times in the day. Furthermore, some research suggests an individual's circadian clock gradually shifts as one ages. Morning chronotypes begin in childhood, but slowly transition to evening chronotypes during young adulthood [1]. However, when one approaches their early $60 \mathrm{~s}$, circadian rhythms begin to revert back to a morning chronotype [1]. Both total sleep time and sleep quality are estimated to decrease beginning from mid-life (ages 36-50) to the eighth decade [9]. Regardless of chronotype, individuals demonstrate superior cognitive performance at their optimal time of day, and deficits in cognitive performance at their suboptimal time of day, a phenomenon known as the synchrony effect [10]. Indeed, morning chronotypes tend to have greater productivity in the morning and poorer productivity in the late evening, while evening chronotypes tend to demonstrate the opposite effect [10]. The synchrony effect can also have a substantial impact on many cognitive abilities in addition to psychological wellbeing. However, literature surrounding this synchrony effect remains unclear.

Therefore, this review paper aims to investigate how age-related changes in circadian rhythms influence cognition and psychological well-being, including mood changes and psychiatric disorders. Circadian rhythm disturbances may pose a risk for cognitive impairment and psychological disorders, particularly in older adults [11]. In terms of cognition, literature was reviewed with respect to the effects of age-related circadian rhythm changes on attention, memory, and executive functioning. These three processes are compromised in healthy aging, and may be further impacted with age-related dysregulations in circadian rhythms.

Literature regarding typical mood changes that are influenced by age-related changes in circadian rhythms are also reviewed, where it is expected that older and younger adults experience better mood during their optimal times of day. Dysregulation of circadian rhythms and sleep-wake disorder increases the susceptibility to numerous moodrelated pathological conditions, such as major depressive disorder (MDD), generalized anxiety disorder (GAD), and bipolar disorder (BP) [12,13]. In fact, recurrent episodes of insomnia or hypersomnia are on the Diagnostic and Statistical Manual of Mental Disorders (DSM-5) diagnostic criteria for GAD [14]. MDD and GAD are psychiatric disorders that share a considerable degree of comorbidity, genetic correlation, and similar pathophysiology [14]. BP is a psychiatric disorder associated with impaired cognition and extreme shifts in mood, behaviour, and energy [13]. Psychological well-being and mood disorders may be further compromised with age-related dysregulation in circadian rhythms.

\section{Methods}

A literature search was conducted using the databases PubMed, PsycINFO, and AgeLine. Studies between the years of 2000 to 2021 were included. Keywords included variations of "circadian rhythms", "aging", "chronotype", "cognition", “depression", "mood", "bipolar disorder", and "anxiety". Studies included data from peer-reviewed journals describing changes in circadian rhythm and age, as well as their direct effects on cognition or psychological well-being. In addition, these studies must include older adults or have a comparison between younger and older adults. Systematic and literature reviews, conference abstracts, and irrelevant articles were excluded.

\section{Results}

A total of 102 relevant articles were initially identified. These studies were screened for eligibility based on their title and abstract. Sixty-four articles remained and were subsequently examined for inclusion criteria, after which 14 studies remained and were ultimately included in the review.

\section{Cognition: Sleep Quality and Synchrony Effect}

Cognitive function is reduced as one's sleep quality diminishes in the aging population [15-18]. Older adults who had poor sleep quality demonstrated a slower speed of processing, poorer executive function, memory, and decreased concentration [15-17]. Some research has shown an association between weaker circadian rhythms in older women and cognitive decline [16].

Much research surrounding cognition has examined the synchrony effect and circadian rhythms [18-22]. Regarding age, younger adults outperformed older adults in all cognitive domains examined, regardless of the time of day [18-20]. Within the domain of memory, time of testing did not significantly differ for younger adult performance; however, this factor was significant for older adults [18,19]. In these studies, older adults had difficulty retrieving memory in the afternoon and evening, but had no difficulty in the morning [18,19]. In a study by May et al., [18] $26 \%$ and $19 \%$ of older adults performed poorly in memory retrieval in the morning and midday, respectively. However, $39 \%$ of older adults performed poorly in memory retrieval at night, which significantly differed between time of day [18]. A separate study by May et al. [21] found similar results, where older adults performed memory tests at their optimal and non-optimal times of day. Younger adults were found to perform better at their optimal time of day in the evening than in the morning, contrasting the previous May et al. [21] study. Two other studies demonstrated similar findings whereby older and younger adults are attentive and alert at their optimal time of day, thereby exemplifying the synchrony effect $[20,22]$. This finding was supported by magnetic resonance imaging, where older adults who tested in the morning demonstrated similar patterns of brain activity in cognitive control regions as young adults did in the evening [20]. In a study by West et al., [22] alertness, which was measured by a subjective alertness rating scale, was greater for younger adults in the evening compared to older adults who were more alert in the morning. Furthermore, older adults who tested in the afternoon 
UNDERGRADUATE RESEARCH IN NATURAL AND CLINICAL SCIENCE AND TECHNOLOGY (URNCST) JOURNAL Read more URNCST Journal articles and submit your own today at: $\underline{\text { https://www.urncst.com }}$

demonstrated decreased resistance to distraction in comparison to the older adults who tested in the morning [20]. Overall, cognitive function diminishes as one ages; however, older adults' cognition is highest during the morning and midday, in comparison to the evening.

\section{Mood Changes}

The literature shows that changes in mood are influenced by time of day. As determined by Schwarz et al., [23] sleep deprivation has profound effects on mood and emotional regulation of both younger (ages 18-30) and older adults (ages 60-72). Regardless of age, there was an expected correlation between sleep deprivation and mood changes, such that sleep-deprived participants felt more fatigued, stressed, and reported lower vigour and positive affect. Both age groups displayed significant increases in total mood disturbances subsequent to sleep deprivation. Although older adults experienced higher levels of mood disturbances following sleep deprivation than younger adults, older adults were more successful at mitigating the associated increased fatigue, mood disturbances, and cognitive attenuation than young adults.

A study conducted by Hill \& Chtourou [24] determined that morning individuals exhibited a significant increase in depression, anger, and fatigue, as well as a decrease in vigour as the day elapsed. Compared to morning individuals, evening individuals demonstrated a significant increase in vigour as the day progressed. Four hundred and thirty five young adults (ages 17-38) and 297 older adults (ages 59-79) were studied to determine whether age differences in chronotype impacted emotional well-being [1]. Regardless of age, morning chronotypes were found to be associated with better overall health compared to those of evening chronotypes. Older morning adults reported significant improvement in mood and higher levels of positive affect as the day progressed, compared to younger evening adults. These studies demonstrate the differences in emotional wellbeing between age groups, namely how older morning adults experience more mood fluctuations throughout the day than their younger counterparts.

\section{Major Depressive Disorder, General Anxiety Disorder, and} Bipolar Disorder

Alterations in circadian rhythms have been observed in individuals with MDD across the lifespan, with an estimated $80 \%$ of this population suffering symptoms of insomnia [25]. Almeida \& Pfaff [26] studied the sleep quality of 1029 participants over the age of 60 , where $36 \%$ reported trouble falling asleep, 54\% reported restlessness, and 35\% reported early morning awakening. Nineteen percent of participants reported sleep difficulties that fell into all three categories. In regards to aging, this study also found that over $60 \%$ of older adults in contact with their general practitioner complained of poor sleep, and these individuals were nearly four times more likely to be depressed than those who did not complain of poor sleep. Within the group of older adults that reported compromised sleep quality, approximately onethird presented with symptoms of depression.

Similarly, sleep disturbances and insomnia have also been observed in individuals with GAD, particularly older adults [12]. In a study by Brenes et al., [27] 110 older adults (ages 60-94) completed the Insomnia Severity Index (ISI), a DSM-4 questionnaire that assesses several categories of sleep, including sleep onset, sleep duration, early morning awakening, and sleep dissatisfaction. A higher score on the ISI indicated greater insomnia symptoms. The ISI scores were found to be highest among individuals diagnosed with GAD, and lowest among individuals without GAD. Sleep disruptions were more common among older adults with GAD, with $52-68 \%$ of participants reporting insomnia, and $90 \%$ of participants reporting poor sleep quality overall. After sleep maintenance, early morning awakening was the second most common complaint associated with sleep difficulties in older adults.

Individuals with BP also experience alterations in sleep, attributed to changes in their circadian rhythms. In a study comparing sleep efficiency of individuals with BP to individuals with insomnia and to healthy controls, Harvey et al. [28] found that the BP group consistently reported longer sleep durations and lower daytime activity than either group. Both the BP and insomnia groups reported lower sleep efficiency scores in comparison to controls. Seventy percent of individuals in the BP group had a clinically significant sleeping problem, with $55 \%$ of the group meeting the criteria to be diagnosed with insomnia. A study conducted by Mansour et al. [29] studied the relationship between chronotype, age of disease onset, and frequency of rapid mood swings (RMS) in a sample of 70 individuals with BP, 80 individuals with schizophrenia, and 349 healthy controls. The study found that the BP group demonstrated agedependent scores, with the highest frequency of evening chronotypes being younger adults with BP. Individuals with BP who experienced RMS expressed evening chronotypes more than those who did not experience RMS. Unlike the control or schizophrenia groups, an earlier BP onset contributed to a greater proportion of evening chronotypes in BP. These studies demonstrate the relationship between altered circadian rhythms and individuals with MDD, GAD and BP, attributing to the notable changes seen in their sleepwake cycles such as reduced sleep quality $[26,27,29]$.

\section{Discussion}

This review demonstrates how age-related changes in circadian rhythms influence cognition and psychological well-being, including mood changes and psychiatric disorders. Various similarities were observed throughout the literature that support the aforementioned age-related disruptions in circadian rhythms. 
UNDERGRADUATE RESEARCH IN NATURAL AND CLINICAL SCIENCE AND TECHNOLOGY (URNCST) JOURNAL Read more URNCST Journal articles and submit your own today at: https://www.urncst.com

\section{Theories Behind Circadian Rhythm Dysfunction}

There are a variety of theories surrounding why circadian rhythms change with age, including dysregulation of the suprachiasmatic nucleus ( $\mathrm{SCN}$ ), decreased sensitivity to light, and reduced circulating melatonin levels [30-35].

The SCN is the principal component within mammals that hosts the internal clock and has the role of being the circadian rhythm oscillator [31]. The SCN regulates endocrine, physiological, and behavioural effects of circadian rhythms, which may all become susceptible to impairments with aging [31]. Both the natural age-related degradation of the SCN and a decrease in vasoactiveintestinal peptide (VP) neurons within the SCN are theorized causes of a deteriorated circadian oscillator [31,36]. Important for circadian function, VP neurons demonstrate a recurring diurnal 24-hour pattern, whereby young adults (under age 50) exhibit low amounts of VP at night and peak values in the morning [31,37]. Contrastingly, the SCN of older adults (above age 50) have reduced total amounts of VP neurons and follow a reversed diurnal cycle, suggesting a disrupted circadian cycle $[31,37]$. The circadian rhythm disruptions that can arise due to a deteriorated SCN are thereby particularly found within the elderly population $[36,37]$.

Melatonin is a hormone secreted by the pineal gland, and has been viewed as a marker of circadian rhythms [33]. In humans, melatonin acts on the SCN to promote sleep by weakening the wake-promoting signals of the circadian clock [38]. Melatonin also acts on the default mode network to induce fatigue and sleep-like changes [38]. It has been widely documented that there is an age-dependent decrease in the nighttime secretion of melatonin as one ages [32-35]. Nighttime melatonin levels in older adults were approximately $50 \%$ lower compared to younger adults in a study by Van Coevorden et al. [34]. Decreased circulation of nighttime melatonin levels are associated with impaired sleep, attributed by the close association between the circadian melatonin system and the circadian sleep system [38]. One explanation for this is the "melatonin replacement" hypothesis, which suggests that increasing melatonin levels will improve sleep overall [38]. This hypothesis supports the relationship between old age, reduced melatonin production, and impaired sleep [38].

Light plays a critical role in one's circadian rhythm; this includes the timing, intensity, and duration of light exposure $[33,39]$. Light is connected to the circadian system through the retina and photoreceptors that connect to the hypothalamus through the retinohypothalamic tract, terminating at the SCN [33]. The strength of the neural and chemical signal to, from, and within the SCN can be affected as one ages, through reductions in retinal light sensitivity and the duration of bright light exposure [33,39]. Reports suggest that older adults receive lower levels of light exposure and a reduced time of light exposure [33]. Older adults can receive approximately $33 \%$ less bright light than younger individuals, according to one study [33]. These reduced levels of bright light have been found to be associated with sleep fragmentation and disordered circadian rhythms [30].

\section{Theoretical Implications}

The literature reviewed supports the idea that as an individual ages, their chronotype gradually shifts from evening to morning. This aligns with research by Biss \& Hasher [1], which examined the gradual shift from evening to morning chronotypes due to changing circadian rhythms related to aging. Furthermore, early morning awakening was one of the most reported complaints associated with sleep difficulties in the study by Brenes et al. [27]. Therefore, the presence of pathological conditions such as MDD and GAD may exacerbate the effects of reduced sleep quality and quantity that older adults experience [26].

Along with the reduced sleep quality in older individuals due to dysregulation of circadian rhythms, poorer sleep quality is correlated with diminished cognitive performance, regardless of chronotype [40]. Importantly, chronotype has an influential role in the pathological conditions examined in this review [40]. Research has suggested behavioural treatments for insomnia are less effective in individuals who exhibit evening than morning chronotypes [41]. Furthermore, there is research to support the association between BP and evening chronotype [13]. By comparing individuals with BP to controls, Mansour et al. [29] demonstrated that individuals with BP were more likely to exhibit evening chronotypes, which is further supported by additional studies [42-44].

\section{Clinical Implications}

As evident in the results, sleep and age are considerable factors in one's mood and behaviour. Therefore, these are important elements for clinicians to take into account when consulting and diagnosing patients, particularly older adults. The findings from this review are clinically relevant, namely due to the prevalence of psychiatric disorders in older adults. Current literature has noted that $1-5 \%$ of the older population suffer from MDD, approximately $2 \%$ have been diagnosed with GAD, and $0.5-1 \%$ of the population are reported to have BP [45-48]. Reduced sleep quality has also been reported within older adults diagnosed with these psychiatric disorders [48]. Thus, it is essential for physicians to acknowledge that sleep quality and disruptions may affect the mood of their patients during clinical evaluations and exacerbate their presenting symptoms.

\section{Occupational and Educational Implications}

Shift work entails working irregular and beyond conventional hours, and is associated with sleep deprivation and extreme fatigue [49-51]. The effects of shift work manifests in various bodily disruptions, such as in circadian rhythms, mood, and cognitive performance [49-51]. As fatigue impacts critical cognitive functioning, shift work can lead to reduced work efficiency, and ultimately increase 
UNDERGRADUATE RESEARCH IN NATURAL AND CLINICAL SCIENCE AND TECHNOLOGY (URNCST) JOURNAL Read more URNCST Journal articles and submit your own today at: https://www.urncst.com

fatigue-related errors and injuries in the workplace [49-51]. This research may inform readers on the various cognitive implications surrounding shift work, such as error-prone behaviours that can decrease workplace productivity. Research suggests that as an individual's shift work experience increases, their performance in immediate recall significantly decreases [50]. However, there is currently no evidence of a correlation of late-life cognitive impairments between individuals who were once long-term shift workers and individuals who were not [52].

Children and adolescents start school early in the morning, which puts students with evening chronotypes at an educational disadvantage [53,54]. The demand to be awake and mentally focused in the morning is particularly difficult for adolescents who perform better at night due to the synchrony effect. Those with evening chronotypes obtain lower grades on average compared to morning chronotypes, and are also more likely to sleep less on school nights, which can further impair cognition, mood, and emotion [3,23,53]. Studies have demonstrated that academic performance can be improved when school times align with adolescent chronotypes and their optimal time of day [54]. For example, Preckel et al. [55] studied how the chronotypes of high school students impacted their academic performance, and found that greater cognition and overall academic achievement were associated with morning chronotypes. In comparison, students with evening chronotypes had a significantly negative association with academic achievements, such as a lower grade point average [55]. From the literature, it is evident that disruptions in circadian rhythms occur throughout the lifespan in an age-dependent manner. Adolescents with morning chronotypes display higher cognitive performance in academia [55]. However, older adults with the same morning chronotype exhibit overall reduced cognitive performance [15-17]. This pattern of findings demonstrates how the interaction between age and chronotype is a crucial factor in cognition, considering older morning adults (and not younger morning adults) exhibit diminished cognitive performance.

\section{Limitations}

A limitation within this review is the low number of studies that were yielded from the literature searches (14 in total). This may be due to the strict inclusion criteria which reduced the number of studies for analysis. More independent studies are needed in order to better understand the cognitive and psychological effects of aging associated with changing circadian rhythms. Additionally, older adults were prioritized in the field of psychiatric disorders, as sleep disturbances are highly prevalent in this population [56]. There is also a lack of longitudinal studies in the literature, which poses a limitation since these studies are useful in observing the same participants over time. It is essential for future literature to measure these changes across the lifespan to have a holistic perspective on this subject matter.

\section{Conclusions}

Therefore, the phrase "the early bird catches the worm" does often apply to older adults, but these circadian changes may also put them at a greater disadvantage to cognitive and psychological decline. There is evidence to support the association between age-related changes in circadian rhythms and their influence on cognition and psychological well-being. Within the domain of cognition, sleep quality diminishes as one ages, which in turn has been associated with poor cognitive performance. Additionally, the synchrony effect is strongly associated with one's age and chronotype, demonstrating positive cognitive performance during an individual's optimal time of testing. Both time of day and circadian rhythm dysfunction vastly influence alterations in mood, whereby sleep deprivation manifests mood disturbances and lowers positive affect. Studies have shown a positive correlation between disrupted circadian rhythms and depression [25,26]. Frequent episodes of insomnia have been observed in MDD and GAD, which is associated with the increased prevalence of sleep disruptions in older adults [27]. Additionally, circadian rhythm dysfunction alters sleep in BP, which is associated with longer sleep duration, yet reduced sleep quality [28]. Future research efforts should focus on the intersections of aging, circadian rhythms, and psychological effects. This can guide both researchers and clinicians in the right direction towards understanding the broad implications circadian rhythm dysfunctions have on overall aging and well-being.

\section{List of Abbreviations Used}

MDD: major depressive disorder

GAD: generalized anxiety disorder

BP: bipolar disorder

DSM: diagnostic and statistical manual of mental disorders

ISI: insomnia severity index

RMS: rapid mood swings

SCN: suprachiasmatic nucleus

VP: vasoactive-intestinal peptide

\section{Conflicts of Interest}

The authors Aoife McMahon, Raymond Tolentino, and Phoebe Thum declare that they have no conflict of interests.

\section{Ethics Approval and/or Participant Consent}

This literature review did not require ethics approval and/or participation consent. As this paper is a review article, the purpose of this study was to summarize and analyze previous articles, as opposed to conducting a primary study. All literature included in this review had previous ethics approval in their respective studies.

\section{Authors' Contributions}

AM: made contributions to the design of the study, collected and analyzed data, drafted the manuscript, and gave final approval of the version to be published. 
UNDERGRADUATE RESEARCH IN NATURAL AND CLINICAL SCIENCE AND TECHNOLOGY (URNCST) JOURNAL Read more URNCST Journal articles and submit your own today at: https://www.urncst.com

RT: made contributions to the design of the study, collected and analyzed data, drafted the manuscript, and gave final approval of the version to be published.

PT: made contributions to the design of the study, collected and analyzed data, drafted the manuscript, and gave final approval of the version to be published.

\section{Acknowledgements}

The authors gratefully acknowledge their mentor, Ricky Chow, for his continuous support and guidance. His generous efforts have not gone unacknowledged and the authors send their utmost appreciation for his contribution to this paper.

\section{Funding}

This study was not funded.

\section{References}

[1] Biss RK, Hasher L. Happy as a lark: Morning-type younger and older adults are higher in positive affect. Emotion. 2012;12(3):437-41. https://doi.org/10.1037\% $2 \mathrm{Fa0027071}$

[2] Froy O. Circadian rhythms, aging, and life span in mammals. Physiology. 2011;26(4):225-35. https://doi.org/10.1152/physiol.00012.2011

[3] Kyriacou CP, Hastings MH. Circadian clocks: Genes, sleep, and cognition. Trends in Cognitive Sciences. 2010 Jun 1;14(6):259-67. https://doi.org/10.1016/ j.tics.2010.03.007

[4] Jagannath A, Taylor L, Wakaf Z, Vasudevan SR, Foster RG. The genetics of circadian rhythms, sleep and health. Human Molecular Genetics. 2017 Jul 14;26(R2):R128-R138. https://doi.org/10.1093/hmg/ddx240

[5] Hood S, Amir S. The aging clock: Circadian rhythms and later life. Journal of Clinical Investigation. 2017;127(2):437-446. https://dx.doi.org/10.1172\%2FJCI90328

[6] Kondratova AA, Kondratov RV. The circadian clock and pathology of the ageing brain. Nature Reviews Neuroscience. 2012;13(5):325-35. https://doi.org/10.1038/nrn3208

[7] Le T, Breitenstein M. Data-driven clinical phenotyping of denosumab exposure in a large United States cohort. 2018 IEEE International Conference on Healthcare Informatics (ICHI). 2018. https://doi.org/10.1109/ICHI.2018.00086

[8] Dijk D-J, Duffy JF. A circadian perspective on human sleep-wake regulation and ageing. In: Borbely AA, Hayaishi O, Sejnowski TJ, Altman JS, eds. The Regulation of Sleep. Strasbourg: Human Frontier Science Program; 2000:212-222.

[9] Cooke JR, Ancoli-Israel S. Chapter 41 - normal and abnormal sleep in the elderly. Handbook of Clinical Neurology. 2011;98:653-65. https://doi.org/10.1016/ b978-0-444-52006-7.00041-1
[10] Nowack K, Van Der Meer E. The synchrony effect revisited: Chronotype, time of day and cognitive performance in a semantic analogy task. Chronobiology International. 2018;35(12):1647-62. https://doi.org/10.1080/07420528.2018.1500477

[11] Reid KJ, McGee-Koch LL, Zee PC. Cognition in circadian rhythm sleep disorders. Progress in Brain Research. 2011 Jan 1;190:3-20. https://doi.org/10.1016/ B978-0-444-53817-8.00001-3

[12] Luik AI, Zuurbier LA, Direk N, Hofman A, Van Someren EJ, Tiemeier H. 24-hour activity rhythm and sleep disturbances in depression and anxiety: A population-based study of middle-aged and older persons. Depression and Anxiety. 2015 Feb 18;32(9):684-92. https://doi.org/10.1002/da.22355

[13] Alloy LB, Nusslock R, Boland EM. The development and course of bipolar spectrum disorders: An integrated reward and circadian rhythm dysregulation model. Annual Review of Clinical Psychology. 2015 Jan 12;11:213-50. https://doi.org/10.1146/annurevclinpsy-032814-112902

[14] Difrancesco S, Lamers F, Riese H, Merikangas KR, Beekman AT, van Hemert AM, Schoevers RA, Penninx BW. Sleep, circadian rhythm, and physical activity patterns in depressive and anxiety disorders: A 2-week ambulatory assessment study. Depression and Anxiety. 2019 Jul 26;36(10):975-86. https://doi.org/ 10.1002/da.22949

[15] Tsapanou A, Gu Y, O'Shea D, Eich T, Tang M-X, Schupf N, et al. Daytime somnolence as an early sign of cognitive decline in a community-based study of older people. International Journal of Geriatric Psychiatry. 2015;31(3):247-55. https://doi.org/10.1002/gps.4318

[16] Walsh CM, Blackwell T, Tranah GJ, Stone KL, AncoliIsrael $\mathrm{S}$, Redline $\mathrm{S}$, et al. Weaker circadian activity rhythms are associated with poorer executive function in older women. Sleep. 2014;37(12):2009-16. https://doi.org/10.5665/sleep.4260

[17] Nebes RD, Buysse DJ, Halligan EM, Houck PR, Monk TH. Self-reported sleep quality predicts poor cognitive performance in healthy older adults. The Journals of Gerontology Series B: Psychological Sciences and Social Sciences. 2009 Mar;64B(2):180-87. https://doi.org/10.1093/geronb/gbn037

[18] May CP, Hasher L. Synchrony affects performance for older but not younger neutral-type adults. Timing \& Time Perception. 2017;5(2):129-48. https://doi.org./10.1163/22134468-00002087

[19] Borella E, Ludwig C, Dirk J, de Ribaupierre A. The influence of time of testing on interference, working memory, processing speed, and vocabulary: Age differences in adulthood. Experimental Aging Research. 2010;37(1):76-107. https://doi.org/10.1080/ 0361073x.2011.536744 
UNDERGRADUATE RESEARCH IN NATURAL AND CLINICAL SCIENCE AND TECHNOLOGY (URNCST) JOURNAL

Read more URNCST Journal articles and submit your own today at: https://www.urncst.com

[20] Anderson JA, Campbell KL, Amer T, Grady CL, Hasher L. Timing is everything: Age differences in the cognitive control network are modulated by time of day. Psychology and Aging. 2014;29(3):648-57. https://doi.org/10.1037/a0037243

[21] May CP, Hasher L, Foong N. Implicit memory, age, and time of day. Psychological Science. 2005;16(2):96-100. https://doi.org/10.1111\%2Fj.09567976.2005.00788.x

[22] West R, Murphy KJ, Armilio ML, Craik FI, Stuss DT. Effects of time of day on age differences in working memory. The Journals of Gerontology Series B: Psychological Sciences and Social Sciences. 2002; 57(1):P3-P10. https://doi.org/10.1093/geronb/57.1.P3

[23] Schwarz J, Axelsson J, Gerhardsson A, Tamm S, Fischer H, Kecklund G, et al. Mood impairment is stronger in young than in older adults after sleep deprivation. Journal of Sleep Research. 2018 Dec 25;28(4). https://doi.org/10.1111/jsr.12801

[24] Hill DW, Chtourou H. The effect of time of day and chronotype on the relationships between mood state and performance in a Wingate test. Chronobiology International. 2020 Sep 14;37(11):1599-610. https://doi.org/10.1080/07420528.2020.1786394

[25] Soria V, Urretavizcaya M. Circadian rhythms and depression. Actas Españolas de Psiquiatría. 2009;37(4):222-32.

[26] Almeida OP, Pfaff JJ. Sleep complaints among older general practice patients: Association with depression. British Journal of General Practice. 2005 Nov 1;55(520):864-6.

[27] Brenes GA, Miller ME, Stanley MA, Williamson JD, Knudson M, McCall WV. Insomnia in older adults with generalized anxiety disorder. The American Journal of Geriatric Psychiatry. 2009 Jun 1;17(6):46572. https://doi.org/10.1097/JGP.0b013e3181987747

[28] Harvey AG, Schmidt A, Scarnà A, Semler CN, Goodwin GM. Sleep-related functioning in euthymic patients with bipolar disorder, patients with insomnia, and subjects without sleep problems. American Journal of Psychiatry. 2005 Jan 1;162(1):50-7. https://doi.org/10.1176/appi.ajp.162.1.50

[29] Mansour HA, Wood J, Chowdari KV, Dayal M, Thase ME, Kupfer DJ, et al. Circadian phase variation in bipolar I disorder. Chronobiology International. 2005;22(3):571-84. https://doi.org/10.1081/CBI200062413

[30] Cooke JR, Ancoli-Israel S. Normal and abnormal sleep in the elderly. Handbook of Clinical Neurology. 2011 Jan 1;98:653-65. https://doi.org/10.1016\%2FB978-0444-52006-7.00041-1

[31] Hofman MA. The human circadian clock and aging. Chronobiology International. 2000 Jan 1;17(3):245-59. https://doi.org/10.1081/CBI-100101047
[32] Hardeland R, Coto-Montes A. New vistas on oxidative damage and aging. The Open Biology Journal. 2010;3:39-52. http://doi.org/10.2174/187419670100 30100039

[33] Myers BL, Badia P. Changes in circadian rhythms and sleep quality with aging: Mechanisms and interventions. Neuroscience \& Biobehavioral Reviews. 1995 Dec 1;19(4):553-71. https://doi.org/10.1016/ 0149-7634(95)00018-6

[34] Van Coevorden A, Mockel J, Laurent E, Kerkhofs M, L'Hermite-Baleriaux M, Decoster C, Neve P, Van Cauter E. Neuroendocrine rhythms and sleep in aging men. American Journal of Physiology-Endocrinology and Metabolism. 1991 Apr 1;260(4):E651-61. https://doi.org/10.1152/ajpendo.1991.260.4.E651

[35] Hardeland R. Melatonin and the theories of aging: A critical appraisal of melatonin's role in antiaging mechanisms. Journal of Pineal Research. 2013 Nov;55(4):325-56. https://doi.org/10.1111/jpi.12090

[36] Mattis J, Sehgal A. Circadian rhythms, sleep, and disorders of aging. Trends in Endocrinology \& Metabolism. 2016 Apr 1;27(4):192-203. https://doi.org/ 10.1016/j.tem.2016.02.003

[37] Hofman MA, Swaab DF. Alterations in circadian rhythmicity of the vasopressin-producing neurons of the human suprachiasmatic nucleus (SCN) with aging. Brain Research. 1994 Jul 18;651(1-2):134-42. https://doi.org/10.1016/0006-8993(94)90689-0

[38] Zisapel N. New perspectives on the role of melatonin in human sleep, circadian rhythms and their regulation. British Journal of Pharmacology. 2018 Aug;175(16):3190-9. https://doi.org/10.1111/bph.14116

[39] Duffy JF, Zeitzer JM, Czeisler CA. Decreased sensitivity to phase-delaying effects of moderate intensity light in older subjects. Neurobiology of Aging. 2007;28(5):799-807. https://doi.org/10.1016/ j.neurobiolaging.2006.03.005

[40] Gobin CM, Banks JB, Fins AI, Tartar JL. Poor sleep quality is associated with a negative cognitive bias and decreased sustained attention. Journal of Sleep Research. 2015 Oct;24(5):535-42. https://doi.org/ $10.1111 /$ jsr.12302

[41] Bei B, Ong JC, Rajaratnam SM, Manber R. Chronotype and improved sleep efficiency independently predict depressive symptom reduction after group cognitive behavioral therapy for insomnia. Journal of Clinical Sleep Medicine. 2015 Sep 15;11(9):1021-7. https://doi.org/10.5664/jcsm.5018

[42] Wood J, Birmaher B, Axelson D, Ehmann M, Kalas C, Monk K, Turkin S, Kupfer DJ, Brent D, Monk TH, Nimgainkar VL. Replicable differences in preferred circadian phase between bipolar disorder patients and control individuals. Psychiatry Research. 2009 Apr 30;166(2-3):201-9. https://doi.org/10.1016/j.psychres .2008 .03 .003 
UNDERGRADUATE RESEARCH IN NATURAL AND CLINICAL SCIENCE AND TECHNOLOGY (URNCST) JOURNAL Read more URNCST Journal articles and submit your own today at: https://www.urncst.com

[43] Ahn YM, Chang J, Joo YH, Kim SC, Lee KY, Kim YS. Chronotype distribution in bipolar I disorder and schizophrenia in a Korean sample. Bipolar Disorders. 2008 Mar;10(2):271-5. https://doi.org/10.1111/j.13995618.2007.00573.x

[44] Bullock B, Corlass-Brown J, Murray G. Eveningness and seasonality are associated with the bipolar disorder vulnerability trait. Journal of Psychopathology and Behavioral Assessment. 2014 Sep 1;36(3):443-51. https://doi.org/10.1007/s10862-014-9414-5

[45] Fiske A, Wetherell JL, Gatz M. Depression in older adults. Annual Review of Clinical Psychology. 2009;5(1):363-89. https://doi.org/10.1146\%2Fannurev .clinpsy.032408.153621

[46] Byers AL, Yaffe K, Covinsky KE, Friedman MB, Bruce ML. High occurrence of mood and anxiety disorders among older adults. Archives of General Psychiatry. 2010;67(5):489. https://doi.org/10.1146/ annurev.clinpsy.032408.153621

[47] Sajatovic M, Strejilevich S, Gildengers A, Dols A, Jurdi R, Forester B, et al. A report on older-age bipolar disorder from the International Society for Bipolar Disorders Task Force. Bipolar Disorders. 2015;17(7):689-704. https://doi.org/10.1111/bdi.12331

[48] Kay D, Dzierzewski J. Sleep in the context of healthy aging and psychiatric syndromes. Sleep Medicine Clinics. 2015;10(1):11-5. https://doi.org/10.1016/ j.jsmc.2014.11.012

[49] Vogel M, Braungardt T, Meyer W, Schneider W. The effects of shift work on physical and mental health. Journal of Neural Transmission. 2012;119:1121-32. https://dx.doi.org/10.1007/s00702-012-0800-4
[50] Rouch I, Wild P, Ansiau D, Marquié J-C. Shiftwork experience, age and cognitive performance. Ergonomics. 2005;48(10):1282-93. https://dx.doi.org/ $\underline{10.1080 / 00140130500241670}$

[51] Caruso CC. Negative impacts of shiftwork and long work hours. Rehabilitation Nursing. 2014;39(1):16-25. https://doi.org/10.1002/rnj.107

[52] Bokenberger K, Ström P, Aslan AKD, Åkerstdet T, Pedersen NL. Shift work and cognitive aging: A longitudinal study. Scandinavian Journal of Work, Environment \& Health. 2017 Sep;43(5):485-93. https://doi.org/10.5271/sjweh.3638

[53]Zerbini G, Merrow M. Time to learn: How chronotype impacts education. PsyCh Journal. 2017;6:263-76. https://doi.org/10.1002/pchj.178

[54] Goldin AP, Sigman M, Braier G, Golombek DA, Leone MJ. Interplay of chronotype and school timing predicts school performance. Nature Human Behaviour. 2020 Apr;4:387-96. https://doi.org/ $\underline{10.1038 / \mathrm{s} 41562-020-0820-2}$

[55] Preckel F, Lipnevich AA, Boehme K, Brandner L, Georgi K, Könen T, Mursin K, Roberts RD.

Morningness-eveningness and educational outcomes: The lark has an advantage over the owl at high school. British Journal of Educational Psychology. 2013 Mar;83(1):114-34. https://doi.org/10.1111/j.2044$\underline{8279.2011 .02059 . x}$

[56] Suzuki K, Miyamoto M, Hirata K. Sleep disorders in the elderly: Diagnosis and management. Journal of General and Family Medicine. 2017;18(2):61-71. https://doi.org/10.1002/jgf2.27

\section{Article Information}

Managing Editor: Jeremy Y. Ng

Peer Reviewers: Ricky Chow, Sumeya Mukhtar

Article Dates: Received Apr 02 21; Accepted Jun 06 21; Published Jun 2421

\section{Citation}

Please cite this article as follows:

McMahon A, Tolentino R, Thum P. Age-related changes in circadian rhythms and their effects on cognition and psychological well-being: A literature review. URNCST Journal. 2021 Jun 24: 5(6).

https://urncst.com/index.php/urncst/article/view/258

DOI Link: https://doi.org/10.26685/urncst.258

\section{Copyright}

(C) Aoife McMahon, Raymond Tolentino, Phoebe Thum. (2021). Published first in the Undergraduate Research in Natural and Clinical Science and Technology (URNCST) Journal. This is an open access article distributed under the terms of the Creative Commons Attribution License (https://creativecommons.org/licenses/by/4.0/), which permits unrestricted use, distribution, and reproduction in any medium, provided the original work, first published in the Undergraduate Research in Natural and Clinical Science and Technology (URNCST) Journal, is properly cited. The complete bibliographic information, a link to the original publication on http://www.urncst.com, as well as this copyright and license information must be included. 


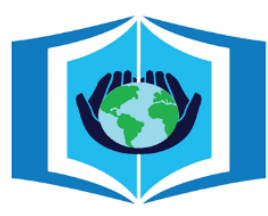

\section{URNCST Journal \\ "Research in Earnest"}

\section{Funded by the \\ Government of Canada}

\section{Canadà̀}

Do you research in earnest? Submit your next undergraduate research article to the URNCST Journal!

| Open Access | Peer-Reviewed | Rapid Turnaround Time | International | | Broad and Multidisciplinary | Indexed | Innovative | Social Media Promoted |

Pre-submission inquiries? Send us an email at info@ urncst.com | Facebook, Twitter and LinkedIn: @URNCST Submit YOUR manuscript today at https://www.urncst.com! 